ISSN 0103-5150

Fisioter. Mov., Curitiba, v. 30, n. 3, p. 519-525, Jul./Sep. 2017

Licenciado sob uma Licença Creative Commons

DOI: http://dx.doi.org/10.1590/1980-5918.030.003.A010

\title{
Prevalence of falls among elderly participants of a health promotion group and comparison of balance tests to detect risk of falls
}

\author{
Prevalência de quedas em idosos participantes de um \\ grupo de promoção da saúde e comparação de testes \\ de equilíbrio na detecção de risco de quedas
}

\author{
Vanessa Lobo Carvalho ${ }^{[a]}$, Analita Alves Clementino ${ }^{[b]}$, Edel Quinn Ferreira Ferro de Magalhães ${ }^{[b]}$, \\ Edlanne Morais Belo da Silva ${ }^{[b]}$, Jussara Almeida de Oliveira Baggio ${ }^{[c]}$ \\ [a] Universidade Estadual de Ciências da Saúde de Alagoas (UNCISAL), Maceió, AL, Brazil \\ [b] Faculdade Estácio de Alagoas (FAL), Maceió, AL, Brazil \\ [c] Centro Universitário Tiradentes (UNIT), Maceió, AL, Brazil
}

\section{Abstract}

Introduction: Falls of elderly people are common, representing a serious public health problem. The use of appropriate instruments in the assessment of elderly patients supports the early detection of individuals under risk of falls and its prevention. Objective: To verify the incidence of falls in a group of elderly patients and detect which balance test is the most appropriate for the studied sample. Methods: Quantitative, crosssectional study with an observational approach. A total of 30 elderly patients aged over 60 years old participating in a health promotion group were included in the sample. The participants were initially interviewed and subsequently assessed by means of the following instruments: Berg Balance Scale (BBS), Timed Up and Go test (TUG), and the Dynamic Gait Index (DGI). Results: The mean age of the participants was $69.30 \pm$

\footnotetext{
* VLC: Doctoral Student, e-mail: carvalhovanessa@hotmail.com AAC: undergrad, e-mail: analitaalves@hotmail.com EQFFM: undergrad, e-mail: edel.kinn@hotmail.com EMBS: BS, e-mail: lanik_1992@hotmail.com JAOB: PhD, e-mail: jussarabaggio@gmail.com
} 
7.47 years; $90 \%$ were women and $46.7 \%$ of the individuals reported falls. The participants obtained a mean value of $10.2 \pm 2.5$ seconds in the TUG, $51.4 \pm 2.6$ in the BBS, and $18.6 \pm 4.2$ in the DGI. The sensitivity of the scales was 0.71 in the TUG, 0.50 in the DGI, and 0.42 in the BBS; specificity was 0.44 in the TUG, 0.32 in the DGI and 0.63 in the BBS. Conclusion: A high prevalence of falls was observed in the sample. In addition, the TUG was the most sensitive test to assess balance in the assessed sample. However, its use alone requires caution in this sample.

Keywords: Postural Balance. Aged. Health Promotion.

\section{Resumo}

Introdução: As quedas em idosos são frequentes e um grave problema de saúde pública. A utilização de instrumentos adequados na avaliação dos idosos auxilia na detecção precoce dos indivíduos em risco de quedas e na sua prevenção. Objetivo: Verificar a ocorrência de quedas em um grupo de idosos e detectar qual o teste de equilíbrio é o mais adequado para a amostra estudada. Métodos: Trata-se de um estudo observacional, transversal do tipo quantitativo. Foram incluídos 30 idosos, acima de 60 anos participantes de um grupo de promoção da saúde. Os participantes foram inicialmente entrevistados e posteriormente avaliados por meio dos seguintes instrumentos: Escala de equilíbrio funcional de Berg (EEB), Timed Up and Go Test (TUG) e Índice Dinâmico da Marcha (DGI). Resultados: A idade média dos participantes foi de 69,30 \pm 7,47 anos, 90\% eram do sexo feminino e 46,7\% dos indivíduos relataram quedas. Os participantes obtiveram valor médio na TUG 10,2 $\pm 2,5$ segundos, na EEB 51,4 $\pm 2,6$ e na DGI de 18,6 \pm 4,2. A sensibilidade das escalas foi de 0,71 na TUG, 0,50 na DGI e 0,42 na EEB e a especificidade foi de 0,44 na TUG, 0,32 na DGI e de 0,63 na EEB. Conclusão: Observou-se uma alta prevalência de quedas na amostra avaliada. Além disso, o TUG foi o teste mais sensível para avaliar o equilíbrio na amostra avaliada. Entretanto, sua utilização de forma isolada merece cautela nessa amostra.

Palavras-chave: Equilíbrio Postural. Idoso. Promoção da Saúde.

\section{Introduction}

In developing countries, like Brazil, aging occurs in a very fast pace (1). Data of the Brazilian Institute of Geography and Statistics (IBGE, as per its acronym in Portuguese), collected between 1991 and 2000, point out an increase of $8.6 \%$ in the number of elderly in the period. In 2000, the population aged over 50 years represented $15.9 \%$ of the total population; in 2010 this number shifted to $20.5 \%$, and by 2050 one fifth of the population will consist of elderly individuals (2).

The aging process generates a series of physiological and pathological changes. One of them consists in the postural imbalance caused by multiple factors such as degradation of the sensory system, central nervous system, and musculoskeletal system (3). Falls represent the main consequence of postural imbalance. In this sense, data point out that $30 \%$ of the individuals aged over 65 years suffer falls at least once a year $(4,5)$.
Falls are considered a serious public health problem that increases financial costs with care activities in the Unified Health System (SUS, as per its acronym in Portuguese), generating a need for an improved support to the elderly (6). In 2008, the population aged over 60 years accounted for 2.18 million hospitalizations, and in 2030 they will account for 4.91 million hospitalizations. The costs would jump from $\mathrm{R} \$ 2.23$ billion to 5.01 billion in this period. These costs are $53.8 \%$ higher than the cost of hospitalization of a child or adolescent (7).

Health Promotion Groups (HPG) consist in a strategy adopted by governmental programs in which the elderly are the target-audience in actions that prioritize primary health care (8 - 10). The HPG may be an instrument for health intervention, serving as a transforming agent in an environment where people share experiences and express their thoughts, feelings, relationships, education in health, as well as for socialization (8). Conceptually, it may be defined 
as a meeting of individuals that interact to improve their knowledge, behavior, and skills, implying an autonomous development to cope with situations that impose suffering, thus minimizing some effects of the aging process (10).

The hypothesis of this study is that the elderly participants of a HPG present a lower prevalence of falls in relation to the elderly population in general. Therefore, the aim of the present study was to verify the prevalence of falls in a group of elderly participants of a health promotion group, and determine the most appropriate balance test to detect the risk of falls in the studied sample.

\section{Methods}

A quantitative, cross-sectional study was conducted with an observational approach. The study was approved by the Research Ethics Committee of Faculdade Estácio de Alagoas, under approval certificate CAAE 28680514.9.0000.5012.

The inclusion criteria were: being 60 years or over, and participating in a health promotion group. Individuals with cognitive disorders and that were not able to walk a 10-meter distance by themselves were excluded. The participants attended a HPG located in a community center. Data were collected from May to July 2014.

Firstly, the explanation of the study methodology and its risks and benefits were provided. The elderly were invited to participate in the study upon signature of a free and informed consent form. Subsequently, an assessment sheet containing 16 items was applied; the items included: age, gender, educational level, the occurrence and place of falls, frequency of falls in the last 6 months, comorbidities (hypertension, diabetes mellitus, rheumatic disease, orthopedic changes, vertigo), use of drugs, and whether or not the patient undergone physical therapy treatment between January and June 2014. After filling this sheet, the Mini-Mental State Examination was conducted to track cognitive disorders.

After the initial interview, the following balance tests were conducted:

- Timed Up \& Go (TUG): an assessment method considered simple and fast that aims at analyzing balance, the ability to perform some motor skills, functional mobility, and the risk of falls. It is widely used to assess elderly patients in relation to their independence. The implementation of the test consists in standing up from a chair, walking a short 3-meter distance, changing the walking direction, and returning to the chair and sitting down (11).

- Berg Balance Scale (BBS): aims at analyzing static and dynamic balance through 14 items, each item containing 5 alternatives ranging from 0 to 4 points. The total score ranges from 0 to 56 points, and the higher the score the better the balance of the assessed individual (12).

- Dynamic Gait Index (DGI): aims at assessing the dynamic balance to quantify the balance skills during the gait. It consists of eight tasks to analyze the quality of the gait in different moments, such as: walking on a flat surface, speed shift, walking with horizontal and vertical head rotation, rotation in their own axis, passing over obstacles, walking around obstacles, and going downstairs and upstairs. Each item of the score ranges from 0 to 3 ; where 3 is considered normal, and 0 is considered as serious impairment, totaling 24 points (13).

The statistical processing was performed through the software SPSS (Statistical Package for the Social Sciences) version 17. The level of significance was set as 5\% (two-tailed) for all the analyses.

Initially, the type of distribution of the variables was tested through the Kolmogorov-Smirnov test. As the balance tests (TUG, BBS and DGI) presented no normal distribution, non-parametric tests were used in the subsequent analyses.

Descriptive statistics was used to show the clinical and demographic characteristics of all the participants. The demographic data and the results of the balance scales of the elderly group were presented through mean scores and standard deviation values for the numeric variables and in percentage for the category variables.

The group of participants was divided into two groups: individuals that reported falls, and individuals that reported no falls. The groups were compared through the Mann-Whitney test.

For the analysis of the balance scales, the area under the ROC curve (Receiver Operating Curve) was calculated, as well as the specificity and sensitivity of each one of them. 


\section{Results}

The HPG consisted of 31 elderly individuals. A total of 30 elderly patients were included in the study, namely 27 female (90\%) and 3 male (10\%) patients. Only 1 individual was excluded for not being able to walk a 10-meter distance without a walking assist device. No participant was excluded due to cognitive impairment.

The mean age of the elderly was $69.30 \pm 7.47$ years. The participants were classified according to their educational level: 8 of them were illiterate $(26.7 \%), 20$ had completed elementary school (66.7\%), 1 completed secondary school (3.3\%), and 1 had completed higher education (3.3\%).

Also, 21 elderly individuals were hypertensive (70\%), 11 had diabetes mellitus (36.7\%), 14 had rheumatic disease $(46.7 \%), 11$ presented vertigo
(36.7\%), 9 reported lack of balance (30\%), 22 reported use of drugs (73.3\%) and 16 had already undergone physical therapy (53.3\%).

Among the assessed elderly, 14 individuals reported falls (46.7\%) within the past 6 months. The mean frequency of falls was $0.86 \pm 1.16$, and the most frequent place of falls were the streets $(36.7 \%)$ and at home $(10.0 \%)$. Among these elderly, 7 fell once (23.3\%), 3 fell twice (10.0\%), 3 fell three times (10.0\%), and 1 fell 4 times (3.3\%).

In relation to the scales, the elderly presented mean score of $10.26 \pm 2.58$ seconds in the TUG, 18.6 \pm 4.27 points in the DGI, and $51.46 \pm 2.63$ points in the BBS.

The studied group was divided as to the presence of falls. The results of both groups are presented in Table 1.

Table 1 - Results of the elderly group with and without falls

\begin{tabular}{lccccc}
\hline & \multicolumn{4}{c}{ With falls $(\mathrm{n}=\mathbf{1 4})$} & \multicolumn{2}{c}{ Without falls $(\mathrm{n}=16)$} \\
\hline Age & Mean & Standard deviation & Mean & Standard deviation & p-value \\
TUG & 70.14 & 8.71 & 68.56 & 6.39 & 0.66 \\
DGI & 10.85 & 2.50 & 9.75 & 2.62 & 0.20 \\
BBS & 17.57 & 5.07 & 19.50 & 3.32 & 0.37 \\
\hline
\end{tabular}

Note: TUG: Timed Up \& Go; DGI - Dynamic Gait Index; BBS - Berg Balance Scale. Mann-Whitney test, significant p-value $\leq 0.05$.

The ROC curve (FIGURES 1, 2 and 3), specificity, and sensitivity were used to assess which scale was the most sensitive to detect the risk of falls in elderly individuals. The area under the ROC curve in the TUG was 0.63 , sensitivity was 0.71 , and specificity was 0.44 for a cut-off score of 9.5 seconds. The DGI evidenced the area under the ROC curve of 0.40 , sensitivity of 0.50 , and specificity of 0.32 for a cut-off score of 18 points; for BBS the area under the ROC curve was 0.44 , sensitivity was 0.42 , and specificity was 0.63 for a cut-off score of 52 points.

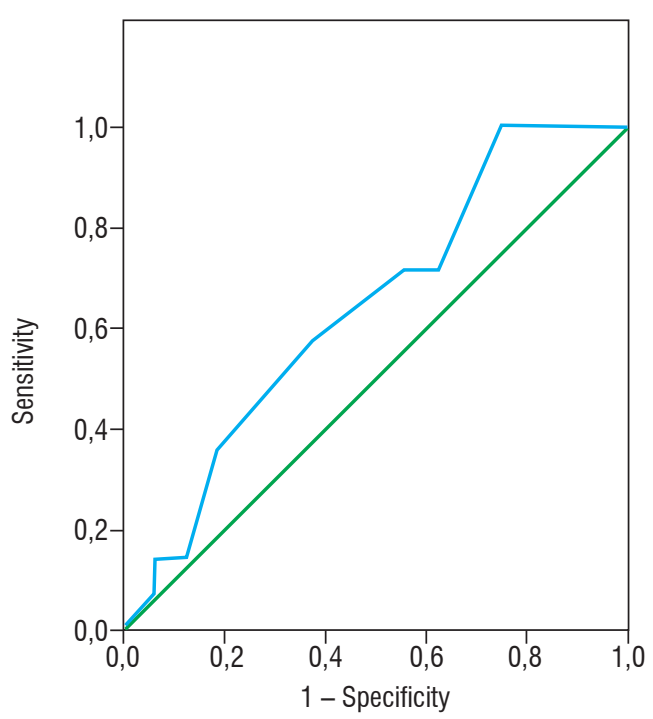

Figure 1 - ROC curve of the TUG. 


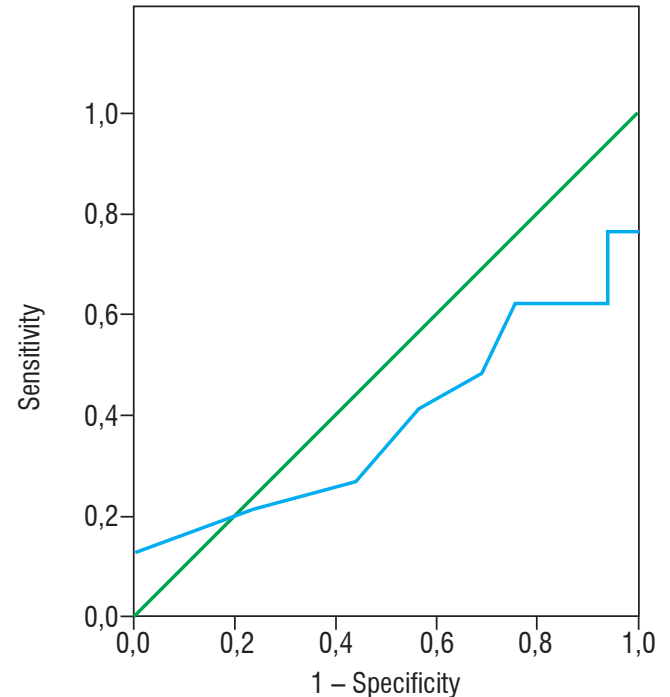

Figure 2 - ROC curve of the DGI.

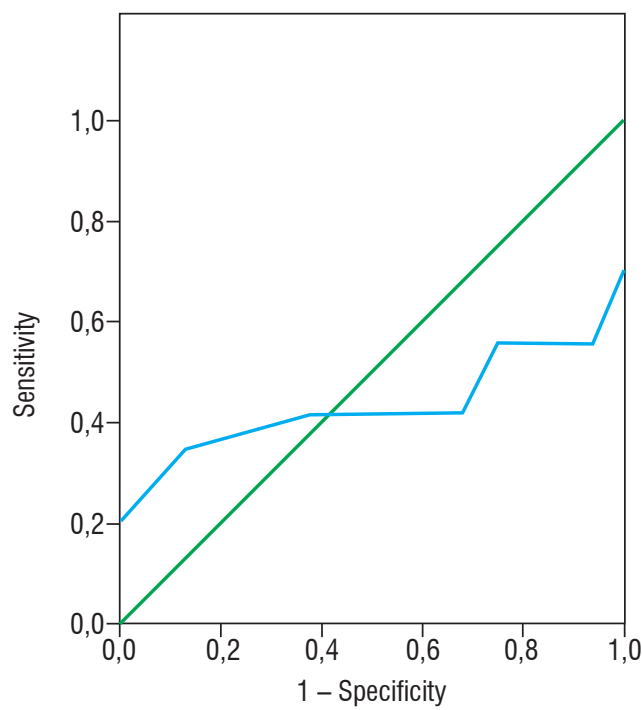

Figure 3 - ROC curve of the BBS.

\section{Discussion}

The aim of the present study was to verify the occurrence of falls in a group of elderly patients participating in a health promotion group. Although these elderly individuals performed physical activities on a regular basis, consisting of stretching, strengthening, balance training, gait, relaxation, and playful activities, $46.7 \%$ reported the occurrence of falls. This prevalence is consistent with a recent review that shows a prevalence of falls among non-institutionalized elderly individuals ranging between $15 \%$ and $56 \%$ (14). These data indicate that falls represent a serious problem that also affects active elderly with good functional levels, therefore requiring a more comprehensive assessment.
With this intent, the present study also aimed at detecting which balance test is the most appropriate for the studied sample. Despite the observed presence of falls, the result of the scales showed that these individuals presented low risk of falls. In all the instruments the mean value of the participants was below the cut-off point mentioned in the literature $(3,11-13,15,16)$. This result may be explained by the characteristics of each instrument.

The BBS has a ceiling or floor effect in some populations. This occurs in groups that present a low level of variability, making the scale ineffective to discriminate individuals with balance impairments (17). Moreover, Kornetti et al. (18) pointed out that some items of the scale are underused, and many of them do not distinguish people with different skills. In this study, the BBS obtained the lowest sensitivity, showing that in this sample the scale is not appropriate to detect changes in the balance of individuals. Thus, the choice for the BBS must be careful in some populations in order to avoid the ceiling or floor effects.

The same happens with the DGI when it is used in elderly with good functional level. Pardasaney et al. (19) pointed out an important ceiling effect of the DGI. The choice for this instrument may be more appropriate in specific populations, such as patients with vestibulopathy $(13,20)$. Sousa et al. (21) observed that nearly $60 \%$ of the individuals assessed with chronic vestibular dysfunctions presented risk of falls.

The TUG was the test that presented the best sensitivity for the studied sample. This is a dynamic test that assesses balance in a simple and quick manner. Although it has been recommended in the last guidelines $(22,23)$ as a screening test to identify elderly patients under risk of fall, a recent systematic review shows that the use of the TUG is limited in elderly living in the community, and that it must not be used as the sole instrument in the identification of individuals under risk of falls (24).

Due to the multifactorial nature of balance (3), several studies point out the use of a protocol for assessment, made up of several instruments, making the assessment more sensitive to detect changes in balance in different populations (24 - 26). Therefore, future studies in this sample could assess the use of the TUG, which obtained the best sensitivity, with other instruments, and verify whether this new protocol is more sensitive to identify changes in balance in a group of elderly participants of a health promotion group. 


\section{Conclusion}

The present study observed a high prevalence of falls in a group of elderly patients participating in a health promotion group. The TUG was found to present the best sensitivity in the evaluation of the most appropriate instrument to identify individuals under risk of falls. However, the use of this instrument alone requires caution, particularly with elderly patients with a good functional level. Thus, further studies investigating the use of the TUG jointly with more appropriate instruments for this population are necessary. Furthermore, the development of new specific instruments to assess elderly patients with a high functional level is critical, as the early detection of individuals with changes in balance may support the planning of a program of physical exercises to prevent falls.

\section{References}

1. Veras R. Envelhecimento populacional contemporâneo: demandas, desafios e inovações. Rev Saúde Pública. 2009; 43(3):548-54.

2. Instituto Brasileiro de Geografia e Estatística (IBGE). Perfil dos idosos responsáveis pelos domicílios no Brasil 2000. 2002 [cited 2014 Jun 4]. Available from: https://tinyurl.com/hgf552r.

3. Shumway-Cook A, Woollacott M. Controle Motor: teoria e aplicações práticas. $2^{\text {nd }}$ ed. São Paulo: Manole; 2003.

4. Gonçalves DFF, Ricci NA, Coimbra AMV. Equilíbrio funcional de idosos da comunidade: comparação em relação ao histórico de quedas. Rev Bras Fisioter. 2009;13(4):316-23.

5. Maia BC, Viana PS, Arantes PMM, Alencar MA. Consequências das quedas em idosos vivendo na comunidade: revisão sistemática. Rev Bras Geriatr Gerontol. 2011;14(2):381-94.

6. Silva AM, Silva RB, Guerra RA, Siqueira GR. Fisioterapia em relação à marcha e ao equilíbrio em idosas. Braz J Health Promot. 2011; 24(3):207-13.

7. Brasil. Departamento de Informática do SUS. Autorizações de Internações Hospitalares. 2009 [cited 2014 Nov 6]. Available from: http://tinyurl.com/ztcbdog.
8. Munari DB, Lucchese R, Medeiros M. Reflexões sobre o uso de atividades grupais na atenção a portadores de doenças crônicas. Cienc Cuid Saude. 2009;8(Suppl):148-54.

9. Horta NC, Sena RR, Silva MEO, Tavares TS, Caldeira IM. A prática de grupos como possibilidade de promoção da saúde no Programa Saúde da Família. Rev APS. 2009;12(3):293-301.

10. Brasil. Ministério da Saúde; Secretaria de Atenção à Saúde. Envelhecimento e saúde da pessoa idosa. Brasília; 2010. Cadernos de Atenção Básica, 19.

11. Podsiadlo D, Richardson S. The timed "up \& go": A test of basic functional mobility for frail elderly persons. J Am Geriatr Soc. 1991;39(2):142-8.

12. Miyamoto ST, Lombardi Jr I, Berg KO, Ramos LR, Natour J. Brazilian version of the Berg balance scale. Braz J Med Biol Res. 2004;37(9):1411-21.

13. Castro SM, Perracini MR, Ganança FF. Versão Brasileira do Dynamic Gait Index. Rev Bra Otorrinolaringol. 2006;72(6):817-25.

14. Sandoval RA, Sá ACAM, Menezes RL, Nakatani AYK, Bachion MM. Ocorrência de quedas em idosos não institucionalizados: revisão sistemática da literatura. Rev Bras Geriatr Gerontol. 2013;16(4):855-63.

15. Paula FL, Alves Jr ED, Prata H. TESTE TIMED "UP AND GO": uma comparação entre valores obtidos em ambiente fechado e aberto. Fisioter Mov. 2007;20(4):143-8.

16. Muir SW, Berg K, Chesworth B, Speechley M. Use of the Berg Balance Scale for predicting multiple falls in community-dwelling elderly people: a prospective study. Phys Ther. 2008;88(4):449-59.

17. Downs, S, Marquez J, Chiarelli P. The Berg Balance Scale has high intra- and inter - rater reliability but absolute reliability varies across the scale: a systematic review. J Physiother. 2013;59(2):93-9.

18. Kornetti DL, Fritz SL, Chiu YP, Light KE, Velozo CA. Rating scale analysis of the Berg Balance Scale. Arch Phys Med Rehabil. 2004;85(7):1128-35

19. Pardasaney PK, Latham NK, Jette AM, Wagenaar RC, PengshengNi, Slavin MD, et al. Sensitivity to Change and Responsiveness of Four Balance Measures for Community-Dwelling Older Adults. Phys Ther. 2012;92(3):388-97. 
20. Whitney SL, Wrisley D, Furman J. Concurrent validity of the berg balance scale and the dynamic gait index in people with vestibular dysfunction. Physiother Res Int. 2003;8(4):178-86.

21. Sousa RF, Gazzola JM, Ganança MM, Paulino CA. Correlação entre equilíbrio corporal e capacidade funcional de idosos com disfunções vestibulares crônicas. Braz J Otorhinolaryngol. 2011;77(6):791-8.

22. Panel on Prevention of Falls in Older Persons, American Geriatrics Society and British Geriatrics Society. Summary of the Updated American Geriatrics Society/ British Geriatrics Society clinical practice guideline for prevention of falls in older persons. J Am Geriatr Soc. 2011;59(1):148-57.

23. Barker W. Assessment and prevention of falls in older people. Nurs Older People. 2014 Jul;26(6):18-24.

24. Barry E, Galvin R, Keogh C, Horgan F, Fahey T. Is the Timed up and go test a useful predictor of risk of falls in community dwelling older adults: a systematic review and meta-analysis. BMC Geriatrics. 2014;14:14.
25. Persad CC, Cook S, Giordani B. Assessing falls in the elderly: should we use simple screening tests or a comprehensive fall risk evaluation? Eur J Phys Rehabil Med. 2010;46(2):249-59.

26. McGinnis PQ Hack LM, Nixon-Cave K, Michlovitz SL. Factors that Influence the Clinical Decision Making of Physical Therapists in Choosing a Balance assessment Approach. Phys Ther. 2009;89(3):233-47.

Received in 12/17/2015

Recebido em 17/12/2015

Approved in 10/25/2016

Aprovado em 25/10/2016 
